\title{
Benzilaminopurina e ácido naftaleno acético na indução e multiplicação in vitro de gemas de abacaxizeiro da cultivar 'IAC Gomo-de-mel'
}

\author{
In vitro bud induction and multiplication of cv. 'IAC Gomo-de-mel' pineapple fruit with benzyl amino \\ purine and $n$ aphthalene acetic acid
}

\author{
Chrystiane Borges Fráguas ${ }^{\mathrm{I}}$ Carolina Martins da Vitória Dornelles ${ }^{\mathrm{I}}$ \\ Giuseppina Pace Pereira Lima ${ }^{\mathrm{I}^{*}}$
}

\section{RESUMO}

O objetivo deste trabalho foi avaliar os efeitos de BAP (6-benzilaminopurina) e NAA (ácido naftaleno acético) na indução, na multiplicação in vitro de gemas, nas brotações de Ananas comosus da cultivar 'IAC Gomo-de-mel' e a correlação desses efeitos com a atividade de peroxidase e o teor de proteína solúvel total. Foram utilizadas gemas axilares retiradas da coroa de frutos sadios, inoculadas em tubo de ensaio contendo meio de cultura MS solidificado com ágar a $5 \%, p H$ ajustado para 5,7, contendo os tratamentos que incluíam diferentes concentrações e combinações de BAP (0, 0,5, 1,0 e 1,5mg $\left.L^{-1}\right)$ e NAA (0, 0,5 e 1,0mg $\left.L^{-1}\right)$. Nessa fase, aos 65 dias, ocorreu a formação de 2,24 brotações, utilizando-se $1 \mathrm{mg} \mathrm{L} \mathrm{L}^{-1}$ de BAP. Após o desenvolvimento, as gemas foram inoculadas em meio MS líquido associado a dois tratamentos $\left(1,0 m g L^{-1} B A P+0,5 m g L^{-1}\right.$ NAA e $1,0 m g L^{-1} B A P+1,0 m g L^{-1}$ NAA) e, aos 95 dias, o meio de cultura mais adequado foi aquele que continha $1,0 \mathrm{mg} L^{-1} B A P+0,5 \mathrm{mg} \mathrm{L}^{-1} \mathrm{NAA}$, proporcionando 7,42 brotações, menor porcentagem de hiperhidricidade, maior número de brotações $e$ indução de gemas. As proteínas solúveis apresentaram relação negativa com hiperhidricidade e comprimento de brotações. A atividade da peroxidase foi maior em plantas com maior número de brotos e com maior porcentagem de hiper-hidricidade.

Palavras-chave: Ananas comosus, cultura de tecidos, peroxidase, hiper-hidricidade.

\section{ABSTRACT}

The objective of this research was to evaluate the effects of BAP (6-benzyl amino purine) and NAA (naphthalene acetic acid) on in vitro buds induction and multiplication on Ananas comosus $c V$. 'IAC Gomo-de-mel' shoots and its correlation with the peroxidase activity and soluble protein content. Axillary buds were excised from the healthy fruits crown and inoculated in $M S$ solidified with agar at $5 \%$ and $p H$ adjusted to 5.7 with the treatments that included different concentrations and combinations of BAP $(0,0.5,1.0$ e $1.5 \mathrm{mg}$ $\left.L^{-1}\right)$ and NAA $\left(0,0.5\right.$ e $\left.1.0 \mathrm{mg} \mathrm{L}^{-1}\right)$. At, 65 days stage, 2.24 shoots were formatted using BAP $1 \mathrm{mg} \mathrm{L}^{-1}$. After bud development, which were inoculated in MS liquid medium associated with two treatments $\left(1.0 \mathrm{mg} \mathrm{L}^{-1} B A P+0.5 \mathrm{mg} \mathrm{L}^{-1}\right.$ $N A A$ e $\left.1.0 \mathrm{mg} \mathrm{L}^{-1} B A P+1.0 \mathrm{mg} \mathrm{L}^{-1} \mathrm{NAA}\right)$. At 95 days the medium more appropriate was $1.0 \mathrm{mg} \mathrm{L}^{-1} B A P+0.5 \mathrm{mg} \mathrm{L}^{-1} \mathrm{NAA}$, providing 7.42 shoots and lower hyperhydricity percentage, more shoots induction and buds. The total soluble proteins showed negative relationship with hyperhydricity and shoots length. The peroxidase activity was higher in plants with more shoots and greater hyperhydricity percentage.

Key words: Ananas comosus, tissue culture, peroxidase, hyperhydricity

\section{INTRODUÇÃO}

A cultivar de abacaxi 'IAC Gomo-de-mel' ou abacaxi-de-gomo é originária da China e provavelmente é resultante de cruzamento natural. Ela foi introduzida no Brasil, em 1991, e é especialmente recomendada para mesa. As pesquisas com essa cultivar são recentes e, até o momento, não há referências sobre a sua micropropagação. Porém, para as cultivares mais comuns, que vêm sendo estudadas a mais tempo, vários trabalhos são encontrados, o que pode auxiliar na pesquisa da cultivar 'IAC Gomo-de-mel' (OMOKOLO et al., 2001).

Usando a técnica de micropropagação com a cultivar 'Pérola', foi possível produzir 161.080 plantas de abacaxi após oito meses, partindo-se de apenas uma planta com oito mudas e 10 gemas axilares cada

'Instituto de Biociências, Universidade Estadual Paulista (UNESP), CP 510, 18618-000, Botucatu, SP, Brasil. E-mail: gpplima@ibb.unesp.br. *Autor para correspondência. 
(ALMEIDA et al., 2002). Essa quantidade é suficiente para o cultivo de abacaxi em uma área de 2,3 ha, em um sistema de plantio adensado (70.000 plantas ha ${ }^{-1}$ ) (SANTANA et al., 2001). Esse grande número de plantas obtido por ALMEIDA et al. (2002) deve-se à otimização do protocolo de micropropagação utilizando o meio MS (MURASHIGE \& SKOOG, 1962) líquido com 1,5 $\mathrm{mg} \mathrm{L}^{-1}$ de BAP (6-benzilaminopurina), que resulta, em média, em 2013,5 brotações por explante após cinco subcultivos. Isso demonstra que estudos sobre multiplicação in vitro de abacaxi são viáveis economicamente.

A aplicação de reguladores vegetais, como as auxinas e as citocininas, é fundamental para promover maior taxa de multiplicação (MACÊDO et al., 2003). Esses reguladores podem estar relacionados à hiperhidricidade (GEORGE, 1996) e esse efeito pode ser vinculado a variações na atividade da peroxidase (SAHER et al., 2004). Assim, as peroxidases podem ser tomadas como substâncias indicadoras de processos bioquímicos (DEBIASI et al., 2007), como divisão celular, crescimento, estresse, etc. (PENEL et al., 1979). Outras substâncias mostram alteração nessas condições, como as proteínas. Geralmente, altos níveis de proteínas podem estar relacionados à taxa de divisão mitótica, pois a síntese de novas proteínas acarreta mudanças morfológicas e bioquímicas durante as fases de crescimento e desenvolvimento (FRANCK et al., 2004).

Este trabalho teve como objetivo avaliar concentrações de BAP e NAA (ácido naftaleno acético) na indução e na multiplicação in vitro de gemas de Ananas comosus da cultivar 'IAC Gomo-de-mel' e correlação dessas concentrações com a atividade de peroxidase e o teor de proteína solúvel total, como possíveis marcadores bioquímicos de hiperhidricidade.

\section{MATERIAL E MÉTODOS}

Foram utilizadas gemas axilares retiradas da coroa de frutos sadios da cultivar 'IAC Gomo-de-mel'. Após a retirada, as gemas foram desinfestadas em câmara de fluxo laminar, por imersão em hipoclorito de sódio comercial ( 2 a 2,5\% de cloro ativo), a $30 \%$, por 20 minutos, sucedida por três enxágües em água destilada e autoclavada. Em seguida, foram inoculadas em tubo de ensaio contendo meio de cultura MS solidificado com ágar a $5 \%, \mathrm{pH}$ ajustado para 5,7 , contendo as combinações de concentrações de $\operatorname{BAP}(0,0,5,1,0$ e $\left.1,5 \mathrm{mg} \mathrm{L}^{-1}\right)$ e NAA $\left(0,0,5\right.$ e $\left.1,0 \mathrm{mg} \mathrm{L}^{-1}\right)$, conforme o tratamento. Os frascos contendo os explantes foram mantidos em sala de crescimento com irradiância em torno de $35 \mu \mathrm{M} \mathrm{m}^{-2} \mathrm{~s}^{-1}$, temperatura de $27 \pm 1^{\circ} \mathrm{C}$ e fotoperíodo de 16 horas.
Após 65 dias, avaliaram-se o número e o comprimento das brotações e a porcentagem de hiperhidricidade. A partir dessas avaliações, foram selecionados os melhores tratamentos para a proliferação das brotações: $1,0 \mathrm{mg} \mathrm{L}^{-1} \mathrm{BAP}+0,5 \mathrm{mg} \mathrm{L}^{-1}$ NAA e $1,0 \mathrm{mg} \mathrm{L}^{-1} \mathrm{BAP}+1,0 \mathrm{mg} \mathrm{L}^{-1} \mathrm{NAA}$. As brotações foram individualizadas, seccionadas e transferidas para meio MS líquido, contendo os tratamentos, em frascos com capacidade para $200 \mathrm{~mL}$, por mais 30 dias. Ao final de 95 dias de cultivo, foram coletadas amostras (brotações) para a análise de peroxidase e proteína solúvel, sendo também avaliados o número e o comprimento de brotações e a porcentagem de hiperhidricidade.

As análises da atividade da peroxidase (EC 1.11.1.7) foram realizadas de acordo com método descrito em DEBIASI et al. (2007). Sobrenadantes (extrato bruto) foram obtidos a partir da homogeneização de amostras de tecido fresco em tampão fosfato $0,2 \mathrm{M} \mathrm{pH} 6,7$ gelado e centrifugados a $4^{\circ} \mathrm{C}$. Foram utilizados, para determinação da atividade, $20 \mathrm{mM}$ de peróxido de hidrogênio, $4 \mathrm{mM}$ de aminoantipirina e $10 \mathrm{mM}$ de fenol, sendo os resultados expressos em ( $\mu \mathrm{mol}$ de $\mathrm{H}_{2} \mathrm{O}_{2}$ decomposto $\mathrm{g}^{-1} \mathrm{~min}^{-1}$ ). Os teores de proteínas totais solúveis foram determinados de acordo com BRADFORD (1976).

O delineamento experimental utilizado foi inteiramente ao acaso, em fatorial $4 \times 3$, com quatro repetições e cinco plantas por parcela. Para as análises bioquímicas, utilizaram-se cinco repetições com uma planta por parcela. Os fatores foram analisados por meio de regressão polinomial ou pelo teste de médias Skott-Knott, com o software estatístico Sisvar (FERREIRA, 2000), usando 5\% de probabilidade de erro.

\section{RESULTADOS E DISCUSSÃO}

Após 12 dias da inoculação das gemas, observou-se o início do desenvolvimento da parte aérea. Aos 65 dias, não houve interação entre as concentrações de NAA e BAP no número de brotações. Houve apenas o efeito simples de BAP para esse parâmetro. Para comprimento das brotações, houve interação significativa entre os reguladores vegetais, indicando o efeito correlacionado dos fatores. Não houve diferença significativa aos 95 dias para número de brotações; porém, pelo teste de Skott-Knott, observou-se diferença significativa para comprimento das brotações. Houve diferença significativa para porcentagem de brotações hiperhídricas, aos 65 e aos 95 dias de cultivo in vitro.

Maior número $(2,32)$ de brotações ocorreu na concentração de $1,29 \mathrm{mg} \mathrm{L}^{-1}$ de BAP (Figura 1A), 


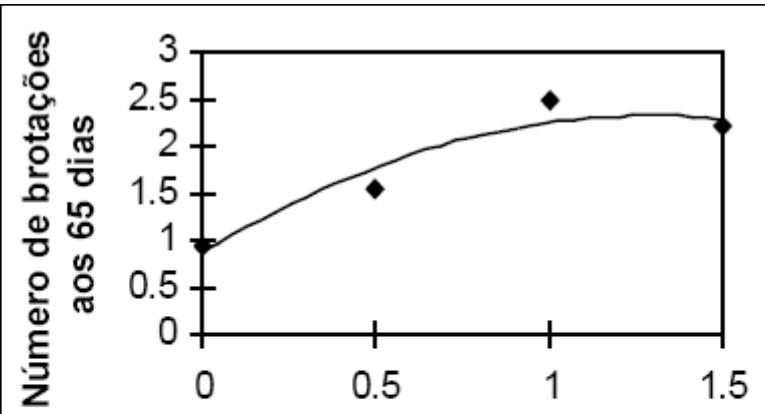

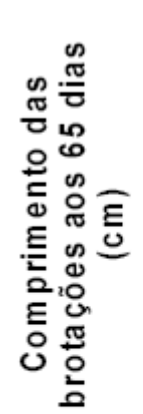

$\mathrm{B}$

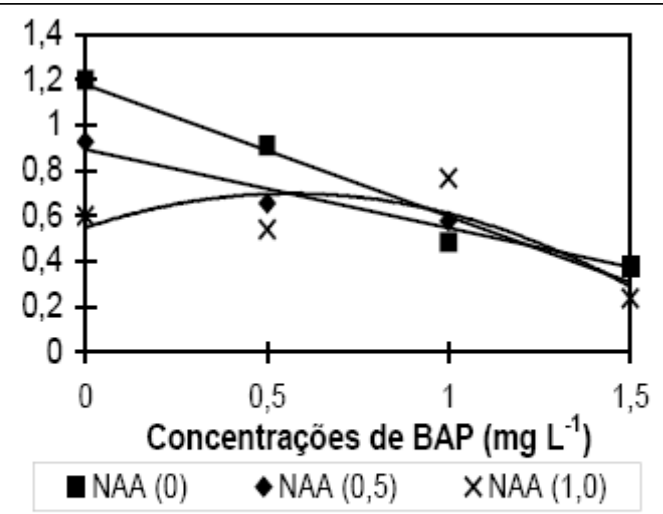

NAA 0: $\mathrm{y}=1,1787-0,5800 \mathrm{x}$

NAA $0,5: y=0,827-0,3445 x$

$\mathrm{R}^{2}=0,96$

$\mathrm{R}^{2}=0,96$

NAA 1,0: $y=0,5477+0,5330 x-0,4700 x^{2} \quad R^{2}=0,80$

Figura 1 - Número (A) e comprimento de brotações (B) de abacaxizeiro 'IAC Gomo-de-mel' cultivadas in vitro por 65 dias sob diferentes concentrações de BAP.

aos 65 dias. Pouca diferença foi verificada quando se utilizou $1 \mathrm{mg} \mathrm{L}^{-1}$ dessa citocinina (2,24 brotações). BAP é uma das citocininas mais utilizadas na indução de brotos (parte aérea) e essencial para o estímulo inicial do desenvolvimento dos ápices caulinares (MALIK et al., 2005). Geralmente, o nível de citocininas é alto em tecidos com capacidade mitótica, sendo necessárias para manter o ciclo de divisão celular e podendo estar envolvidas na promoção da diferenciação celular (WERNER et al., 2001).

Para a cultivar 'Cayenne', as concentrações de $4 \mathrm{mg} \mathrm{L}^{-1}$ de BAP e $6 \mathrm{mg} \mathrm{L}^{-1}$ de cinetina foram as melhores para a indução de brotações (OMOKOLO et al., 2001), enquanto que $1,5 \mathrm{mg} \mathrm{L}^{-1}$ de BAP foi a melhor concentração para o estádio de multiplicação (ALMEIDA et al., 2002), diferentemente do encontrado neste trabalho para a cultivar 'Gomo-de-mel'. As diferenças relatadas podem estar relacionadas com a composição do meio nutritivo utilizado na micropropagação de abacaxizeiro e com a variabilidade genética apresentada pelas diferentes cultivares.

Brotações cultivadas no meio MS, na ausência de reguladores, apresentaram maior comprimento (Figura 1B), porém não houve proliferação de brotos, sendo, portanto inviável de utilizar para fins de micropropagação. Com o aumento das concentrações de BAP, ocorreu diminuição no comprimento das brotações, para todas as concentrações de NAA utilizadas. Resultado normalmente observado por diversos autores (MACÊDO et al., 2003; FRÁGUAS et al., 2004). BAP tem sido eficaz para promover a multiplicação em diversas espécies e parece responsável pela multiplicação de partes aéreas e indução de gemas adventícias, além de ser a citocinina mais barata de todas. Porém, seu excesso é tóxico e caracteriza-se, principalmente, pela falta de alongamento das culturas, pela redução no tamanho das folhas, pelo encurtamento dos entrenós, pelo engrossamento exagerado dos caules e pela hiperhidricidade generalizada, o que leva a problemas sérios na fase de enraizamento (GRATTAPAGLIA\& MACHADO, 1998).

Utilizando-se o meio $\mathrm{MS}+1,0 \mathrm{mg} \mathrm{L}^{-1} \mathrm{BAP}+$ $0,5 \mathrm{mg} \mathrm{L}^{-1} \mathrm{NAA}$, verificou-se uma média de $0,53 \mathrm{~cm}$ de comprimento das brotações, enquanto que a combinação de $\mathrm{MS}+1,0 \mathrm{mg} \mathrm{L}^{-1} \mathrm{BAP}+1,0 \mathrm{mg} \mathrm{L}^{-1} \mathrm{NAA}$ proporcionou uma média de $0,61 \mathrm{~cm}$ (Figura 1B). As menores brotações ocorreram nos tratamentos que continham 1,5 $\mathrm{mg} \mathrm{L}^{-1}$ de BAP, independentemente da concentração de NAA utilizada (Figura 1B). Os resultados revelaram relação inversa entre comprimento e número de brotações.

$\mathrm{O}$ uso de BAP e NAA $\left(1,0\right.$ e $0,5 \mathrm{mg} \mathrm{L}^{-1}$, respectivamente), aos 65 dias, apresentou como vantagem um maior número de brotos. Entretanto, de acordo MACÊDO et al. (2003), tratamentos de concentrações intermediárias (BAP $0,5 \mathrm{mg} \mathrm{L}^{-1}+0,25 \mathrm{mg}$ $\mathrm{L}^{-1}$ de NAA) e menores $\left(0,25 \mathrm{mg} \mathrm{L}^{-1} \mathrm{BAP}+0,12 \mathrm{mg} \mathrm{L}^{-1} \mathrm{de}\right.$ NAA) são os mais indicados para serem adicionados ao meio de cultura devido à maior facilidade de individualização dos brotos, já que concentrações como a recomendada para a cultivar 'Gomo-de-mel' podem promover a formação de muitas brotações unidas entre si, dificultando o processo de individualização.

Ciência Rural, v.39, n.6, set, 2009. 
Aos 95 dias, observou-se um aumento no número de brotos, se comparado com os dados obtidos para 65 dias. Esse efeito pode ser atribuído, provavelmente, ao acúmulo de citocinina do cultivo anterior, comumente denominado efeito residual (FRÁGUAS et al., 2004), porém não houve diferença estatística para número de brotos entre os tratamentos utilizados (Tabela 1). Outra hipótese para esse aumento de brotos seria devido ao cultivo em meio líquido nessa fase. De acordo com GRUPTA et al. (1981), a utilização de meio líquido facilita a absorção de nutrientes pela planta devido a sua distribuição no meio de cultura. Assim, maiores taxas de proliferação de brotos neste trabalho estariam relacionadas à melhor absorção de nutrientes. Resultados similares foram observados por GUERRA et al. (1999), que relataram aumento na multiplicação de brotos de abacaxizeiro 'Perolera' ao utilizarem meio MS líquido e $0,5 \mathrm{mg} \mathrm{L}^{-1} \mathrm{de} \mathrm{NAA}+1,0 \mathrm{mg}$ $\mathrm{L}^{-1}$ de BAP e por ALMEIDA et al. (2002), com a cultivar 'Pérola'.

O número de brotos encontrado poderia também ser atribuído ao estímulo à divisão celular causado pelo seccionamento que, possivelmente, contribuiu para o desenvolvimento de gemas adventícias e, consequentemente, promoveu aumento no número de brotações produzidas pelo explante. $\mathrm{O}$ seccionamento das brotações nas regiões meristemáticas pode induzir a divisão celular, devido à alta capacidade mitótica dessas células (GEORGE, 1996). O uso de $1,0 \mathrm{mg} \mathrm{L}^{-1} \mathrm{BAP}+1,0 \mathrm{mg} \mathrm{L}^{-1} \mathrm{NAA}$ induziu plantas com aspecto hiperhídrico mais acentuado em comparação com o tratamento contendo $1,0 \mathrm{mg} \mathrm{L}^{-1} \mathrm{BAP}$ $+0,5 \mathrm{mg} \mathrm{L}^{-1} \mathrm{NAA}$, caracterizando este último como melhor tratamento para a fase de multiplicação da cultivar 'IAC Gomo-de-mel' (tanto aos 65, quanto aos 95 dias) (Figura 2 e Tabela 1). As plantas hiperhídricas apresentam alterações anatômicas e morfológicas, tais como: deficiência de cloroplastos, pouca cera epicuticular, baixo nível de lignina e celulose, baixa resistência da parede celular (FRANCK et al., 2004), aspecto vítreo, tamanho reduzido e folhas intumescidas e quebradiças (MAJADA et al., 2001).

Alguns trabalhos relacionam a presença de altas concentrações de citocinina e/ou auxina à hiperhidricidade (PICOLI et al., 2001), e, geralmente, existe uma relação negativa entre altura das brotações, proliferação e hiper-hidricidade. No entanto, neste trabalho, foi observada uma tendência de maior número de brotos no tratamento, sendo destacada maior porcentagem de hiperhidricidade. Por outro lado, esse efeito também pode ser atribuído à presença de BAP. O mecanismo de ação da citocinina no processo da vitrificação é pouco compreendido, mas parece que esse regulador induz um aumento da divisão celular (WILLIAMS \& TAJI, 1991) e, em meio com alto potencial hídrico e/ou uma atmosfera de elevada umidade relativa (como encontrada no interior dos frascos), ocorre a formação de novas células, que logo se tornariam túrgidas (PICOLI et al., 2001).

Outros fatores podem ter promovido essa alta porcentagem de células hiperhídricas, tais como a composição do meio de cultura, o selamento dos frascos e os reguladores vegetais, os quais, por meio do conhecimento das técnicas, poderiam ser utilizados para reverter a hiperhidricidade (TÓTH et al., 2004). Em plantas de batata cultivadas, em frascos completamente selados, ocorreram sintomas severos de hiperhidricidade, sendo os níveis internos de etileno significativamente maiores (PARK et al., 2004)

A hiperhidricidade tem sido relacionada com o teor de proteínas em alguns trabalhos. O maior teor de proteína total solúvel ocorreu no tratamento

Tabela 1 - Número e comprimento $(\mathrm{cm})$ de brotações, porcentagem de hiperhidricidade, teor de proteína total solúvel e atividade de peroxidase de abacaxizeiro 'IAC Gomo-de-mel' cultivados in vitro aos 95 dias.

\begin{tabular}{|c|c|c|c|c|}
\hline & $\begin{array}{l}1,0 \mathrm{mg} \mathrm{L}^{-1} \mathrm{BAP}+0,5 \mathrm{mg} \mathrm{L}^{-1} \\
\text { NAA }\end{array}$ & $\begin{array}{l}1,0 \mathrm{mg} \mathrm{L}^{-1} \mathrm{BAP}+1,0 \mathrm{mg} \mathrm{L}^{-1} \\
\text { NAA }\end{array}$ & CV $(\%)$ & Média Geral \\
\hline Número de brotos & $7,42 \mathrm{a}$ & 9,03 a & 6,24 & 8,22 \\
\hline Comprimento dos brotos $(\mathrm{cm})$ & $0,84 \mathrm{a}$ & $0,70 \mathrm{~b}$ & 4,32 & 0,77 \\
\hline Hiperhidricidade $(\%)$ & $70 \mathrm{~b}$ & $85 \mathrm{a}$ & 7,42 & 55,00 \\
\hline $\begin{array}{l}\text { Teor de proteína } \\
\left.\text { ( } \mu \mathrm{g} \text { de proteína } \mathrm{g}^{-1} \mathrm{~m} . \mathrm{f} .\right)\end{array}$ & 586,29 a & $328,68 \mathrm{~b}$ & 13,21 & 457,48 \\
\hline Atividade de peroxidase & & & & \\
\hline $\begin{array}{l}\text { ( } \mu \text { mol de } \mathrm{H}_{2} \mathrm{O}_{2} \text { decomposto } \min ^{-1} \mathrm{mg}^{-1} \\
\text { proteína) }\end{array}$ & $1 \times 10^{-5} \mathrm{~b}$ & $2,9 \times 10^{-5} \mathrm{a}$ & 8,43 & 0,0000194 \\
\hline
\end{tabular}

Médias não seguidas por mesma letra, na linha, diferem significativamente entre si pelo teste de Scott-Knott, em nível de 5\% de probabilidade de erro. 


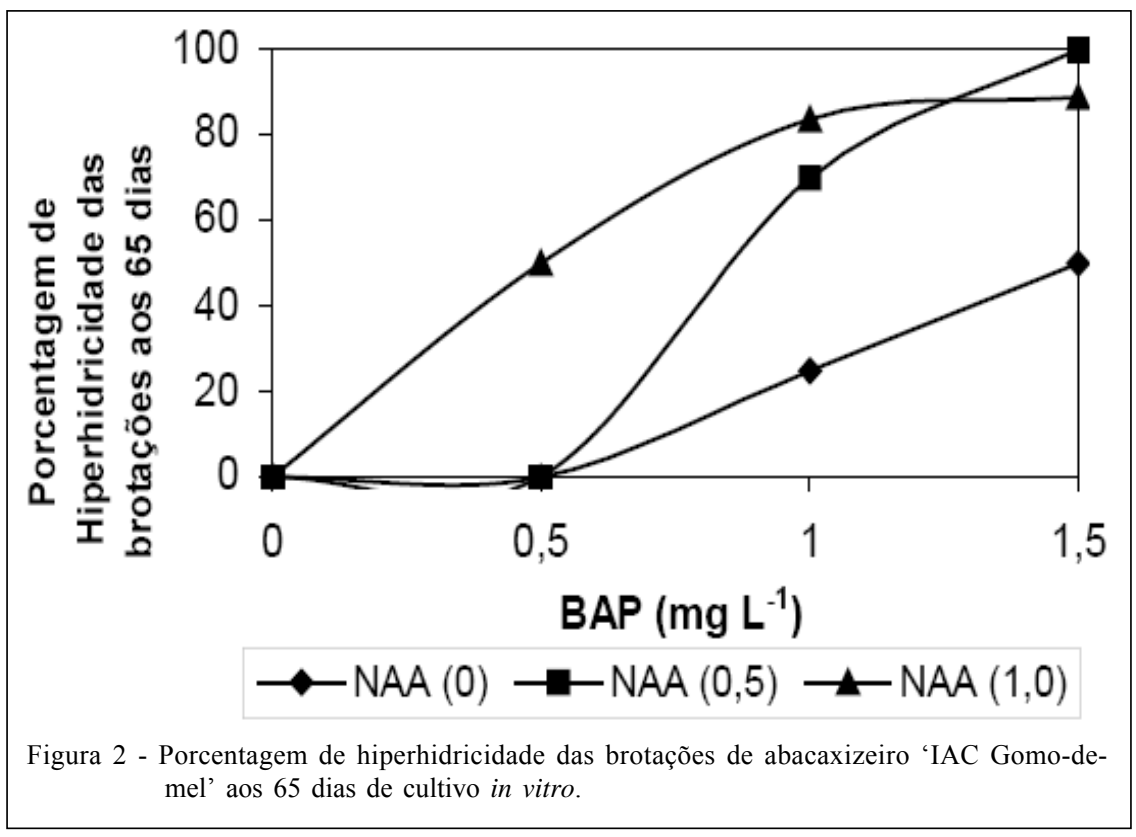

contendo 1,0mg L-1 BAP + 0,5mg L-1 NAA (Tabela 1). Possivelmente, a redução no teor de proteína, no tratamento contendo $1,0 \mathrm{mg} \mathrm{L}^{-1} \mathrm{BAP}+1,0 \mathrm{mg} \mathrm{L}^{-1} \mathrm{NAA}$, esteja relacionada à maior porcentagem de hiperhidricidade. Resultados semelhantes foram observados por PICOLI et al. (2001), em folhas hiperhídricas de Solanum melongena. Contudo, outros trabalhos mostram que o conteúdo de proteínas, em plantas vitrificadas, é superior ao das plantas normais (PHAN \& LETOUZÉ, 1983).

Com relação à peroxidase, verificou-se maior atividade no tratamento $1,0 \mathrm{mg} \mathrm{L}^{-1} \mathrm{BAP}+1,0 \mathrm{mg} \mathrm{L}^{-1} \mathrm{NAA}$ (Tabela 1), possivelmente, devido à maior porcentagem de hiperhidricidade das brotações, provocando acúmulo de peróxido de hidrogênio dentro das células e resultando em condição de estresse (LIMA et al., 1999). Esses resultados estão de acordo com os observados por PIQUERAS et al. (2002), em brotações hiperhídricas de Dianthus caryophyllus.

Há relatos que a maior atividade de peroxidase, em brotações hiperhídricas de diversas espécies, poderia estar relacionada ao etileno (FRANCK et al., 2004), e a presença desse hormônio estaria relacionada ao aumento da atividade das peroxidases básicas, conhecidas por se ligarem às membranas (PENEL et al., 1979). Outros autores também descreveram um aumento no etileno, em tecidos hiperhídricos, e relacionaram o aumento do conteúdo dessa substância ao aumento da produção de peróxido de hidrogênio e, consequentemente, a um aumento na atividade da peroxidase (SAHER et al., 2004).

\section{CONCLUSÕES}

$\mathrm{O}$ meio de cultura mais adequado para a micropropagação de abacaxi 'Gomo-de-mel' é o MS líquido associado a $1,0 \mathrm{mg} \mathrm{L}^{-1} \mathrm{BAP}+0,5 \mathrm{mg} \mathrm{L}^{-1} \mathrm{NAA}$, proporcionando menor porcentagem de hiperhidricidade, maior número de brotações e maior indução de gemas. Proteínas solúveis apresentam relação negativa com hiperhidricidade e comprimento de brotações. A atividade da peroxidase é maior em plantas com maior número de brotos e com maior porcentagem de hiperhidricidade.

\section{REFERÊNCIAS}

ALMEIDA, W.A.B. et al. Optimization of a protocol for the micropropagation of pineapple. Revista Brasileira de Fruticultura, v.24, n.2, p.296-300, 2002.

BRADFORD, M. A rapid and sensitive method for the quantification of microgram quantities of protein utilizing the principle of protein-dye binding. Analytical Biochemistry, v.72, p.248-254, 1976.

DEBIASI et al. Estudo das poliaminas na morfogênese in vitro de Hemerocallis sp. Ciência Rural, v.37, n.4, p.10141020, 2007. Disponível em: <http://www.scielo.br/ s c i e lo.ph p s c ri p t $=$ s c i a r t t ext \& pi d = S 0103 $84782007000400015 \& \operatorname{lng}=\mathrm{pt} \& \mathrm{nrm}=\mathrm{iso}>$. Acesso em: 27 mar. 2009. Doi: 10.1590/S0103-84782007000400015.

FERREIRA, D.F. Análises estatísticas por meio do Sisvar para Windows versão 4. 0. In: REUNIÃO ANUAL DA REGIÃO BRASILEIRA DA SOCIEDADE INTERNACIONAL DE BIOMETRIA, 45., 2000, São Carlos. Anais... São Carlos: UFSCar, 2000. p.255-258.

Ciência Rural, v.39, n.6, set, 2009. 
FRÁGUAS, C.B. et al. Micropropagation of fig (Ficus carica) 'Roxo de Valinhos' plants. In Vitro Cellular and Developmental Biology - Plant, v.40, n.5, p.471-474, 2004.

FRANCK, T. et al. Hyperhydricity of Prunus avium shoots cultured on gelrite: a controlled stress response. Plant Physiology and Biochemistry, v.42, p.519-527, 2004. Disponível em: <http://www.sciencedirect.com/ science? ob=ArticleURL\&_udi=B6VRD-4CK1RF9$3 \& \_$user $=972052 \& \_$rdoc $=1 \&$ fmt $=\& \_$orig $=$search\&_sort $=d \&$ view $=c \&$ a c c t $=$ C $000049647 \& \quad$ version $=1 \&$ ur 1 Versi $\overline{\text { on }}=0 \&$ userid $=972052 \& \mathrm{md} 5=\mathrm{c} 28 \overline{7} \mathrm{ac} 45774 \mathrm{ae} 89 \mathrm{e} 778542 \mathrm{~d} 0 \mathrm{~d} 805024 \mathrm{~d}>$ Acesso em: 27 mar. 2009. Doi:10.1016/j.plaphy.2004.05.003.

GEORGE, E.F. Plant propagation by tissue culture. Part 1. England: Exegetics, 1996. 327p.

GRUPTA, P.K. et al. Tissue culture of forest trees clonal propagation of mature trees of Eucalyptus citriodora Hook, by tissue culture. Plant Science Letters, v.20, p.195-201, 1981.

GUERRA, M.P. et al. Estabelecimento de um protocolo para a micropropagação do abacaxizeiro. Pesquisa Agropecuária Brasileira, v.34, n.9, p.1557-1563, 1999.

GRATTAPAGLIA, D.; MACHADO, M. A. Micropropagação. In: TORRES, A. et al. (Ed.). Cultura de tecidos e transformação genética de plantas. Brasília-DF: Embrapa, 1998. V.1, p.183-260.

LIMA, G.P.P. et al. Poliaminas e atividade da peroxidase em feijão (Phaseolus vulgaris L.) cultivado sob estresse salino. Scientia Agrícola, v.56, n.1, p.21-25, 1999.

MACÊDO, C.E.C. et al. Concentrações de ANA e BAP na micropropagação de abacaxizeiro L. Merrill (Ananas comosus) e no cultivo hidropônico das plântulas obtidas in vitro. Revista Brasileira de Fruticultura, v.25, n.3, p.501-504, 2003. Disponível em: $<$ http:/ $/$ www.scielo.br/scielo.php?script $=$ sci arttext\&pid $=\mathrm{S} 0100$ $29452003000300035 \& \operatorname{lng}=$ en\&nrm $=$ iso $>$. ISSN $0100-2945$. Acesso em: 27 mar. 2009. Doi: 10.1590/S0100-29452003000300035.

MAJADA J.P. et al. Air exchange rate affects the in vitro developed leaf cuticle of carnation. Science Horticulturae, v.87, p.121-130, 2001

MALIK, S.K. et al. Rapid in vitro multiplication and conservation of Garcinia indica: A tropical medicinal tree species. Scientia Horticulturae, v.106, p.539-553, 2005. Disponível em: <http://www.sciencedirect.com/ science? ob=MImg\& imagekey=B6TC $3-4$ H 16 P9K-1$5 \&$ \& di $=5159 \&$ \& user $=972052 \&$ orig $=$ browse\&_cov erDate $=11 \% 2 \mathrm{~F} 01 \% 2 \mathrm{~F} 2005 \&$ sk $=998939995 \&$ view=c\&wchp=dGLbVzzzSkWz\&md5=020fc0f9d69f5edc36f8 1 de $1592 \mathrm{e} 9 \mathrm{dbb} \& \mathrm{ie}=/$ sdarticle.pdf $>$. Acesso em: 27 mar. 2009. Doi:10.1016/ j.scienta.2005.05.002

MURASHIGE, T.; SKOOG, F. A revised medium for rapid growth and bioassays with tobacco tissue culture. Physiologia plantarum, v.15, p.473-497, 1962
OMOKOLO, N.D. et al. Régénération directe in vitro de l'Ananas comosus (L.) Merril var. Cayenne à partir de couronnes cultivées en milieu liquide. Fruits, v.56, p.415-421, 2001.

PARK, S.W. et al. Effect of sealed and vented gaseous microenvironment on hyperhydricity of potato shoots in vitro. Scientia Horticulturae, v.99, p.199-205, 2004. Disponível em: <http://www.sciencedirect.com/ science?_ob=MImg\&_imagekey=B6TC3-49SWCMW-1B\& cdi $=5159 \&$ user $=972052 \&$ orig $=$ browse\& coverD ate $=02 \% 2 \mathrm{~F} 06 \% 2 \mathrm{~F} 2004 \&$ sk $=999009997 \& \mathrm{view}=\mathrm{c} \& w c h p=\overline{d G L z V t z}-$ zSkzk\&md5 $=577760536193$ bc56a065a3c55d2f2098\&ie $=$ sdarticle.pdf $>$. Acesso em: 27 mar. 2009. Doi:10.1016/S0304 4238(03)00097-9.

PENEL, C. et al. Role du calcium dans l'association des peroxidases à des membranes de raciness de lentille. Comptes Rendus de l'Académie des Sciences, v.289, p.29-33, 1979.

PHAN, C.T.; LETOUZÉ, R. A comparative study of chlorophyll, phenolic and protein contents and of hydroxinnamate: CoA activity of normal and vitreous plants (Prunus avium L.) obtained in vitro. Plant Science Letters, v.31, p.323-327, 1983

PICOLI, E.A.T. et al. Hyperhydricity in in vitro eggplant regenerated plants: structural characteristics and involvement of BiP (Binding Protein). Plant Science, v.160, p.857-868, 2001.

PIQUERAS, A. et al. Polyamines and hyperhydricity in micropropagated carnation plants. Plant Science, v.162, p.671-678, 2002.

SAHER, S. et al. Hyperhydricity in micropropagated carnation shoots: the role of oxidative stress. Physiologia Plantarum, v.120, n.1, p.152-161, 2004.

SANTANA, L.L de A. et al. Altas densidades de plantio na cultura do abacaxi cv. Smooth Cayenne, sob condições de sequeiro. Revista Brasileira de Fruticultura, v.23, n.2, p.353-358, 2001. Disponível em: <http://www.scielo.br/ scielo.php?script=sci_arttext\&pid=S 0100 $29452001000200031 \& \operatorname{lng}=\mathrm{en} \& \mathrm{nrm}=\mathrm{iso}>$. Acesso em: 27 mar. 2009. Doi: 10.1590/S0100-29452001000200031.

TÓTH, S. et al. Effective and reproducible protocols for in vitro culturing and plant regeneration of the physiological model plant Ramonda myconi (L.) Rchb. Plant Science, v.166, p.10271034, 2004. Disponível em: <http://www.springerlink.com/ content/d23mb707e07u0wex/> Acesso em: 27 mar. 2009. Doi: 10.1007/s00299-002-0479-3.

WERNER, T. et al. Regulation of plant growth by cytokinin. Proceedings of the National Academy of Sciences of the United States of America, v.98, p.10487-10492, 2001.

WILLIAMS, R.R.; TAJI, A.M. Effect of temperature, ge concentration and cytokinins on vitrification of Olearia microdisca (J.M. Black) in vitro shoot cultures. Plant Cell Tissue and Organ Culture, v.26, p.1-6, 1991. Disponível em: <http://www.springerlink.com/content/x21x5628h3473731/ Acesso em: 27 mar. 2009. Doi:10.1007/BF00116601. 